\title{
Dr William Buchan (1729-1805) and his Domestic medicine
}

Peter M Dunn

William Buchan was born in Ancram in Roxburghshire in 1729 where his father had a small estate. ${ }^{1}$ Even during his school days he acted as amateur doctor to the village. In about 1749 , he went to Edinburgh to study divinity, supporting himself by teaching mathematics to fellow students. Changing to the study of medicine under the elder Gregory, he qualified around 1758. The following year he was appointed as the first surgeon and apothecary to a branch of the Foundling Hospital that had opened that year in Ackworth, Yorkshire. His salary was $£ 42$ a year, exclusive of his board and his horse! This post provided him with great experience in the care of children. While there, Buchan wrote his MD dissertation for Edinburgh University $O n$ the preservation of infant life (1761). His stay at Ackworth ended abruptly when Parliament discontinued its financial support for the Foundling Hospital. Thereafter, he practised for some years in Sheffield before returning to Edinburgh in 1766 (fig 1). Besides continuing to practise, he gave lectures on natural philosophy, which were very popular and drew large classes. In 1769 he published his great work, Domestic medicine or the family physician, ${ }^{2}$ the first work of its kind. It sold for just 6 shillings. Its success was immediate, and 80000 copies from the 19 English editions were sold during his lifetime. In addition, it was translated into all the main European languages including Russian. Indeed the Empress of Russia was so pleased with it that she sent Buchan a letter of commendation and a gold medal.

Although the therapeutic remedies of Domestic medicine were often no better than those in current use at that time, in terms of achieving positive health and preventing disease, the text was far, far ahead of its day. Buchan was also critical of the profession for making a mystery of their art, as this extract reveals:

\section{On the medical profession ${ }^{2}$}

"Medical authors have generally written in a foreign language; and those who were unequal to the task, have even valued themselves upon couching, at least, their prescriptions, in terms and characters unintelligible to the rest of mankind ... Disguising medicine not only retards its improvement as a science, but exposes the profession to

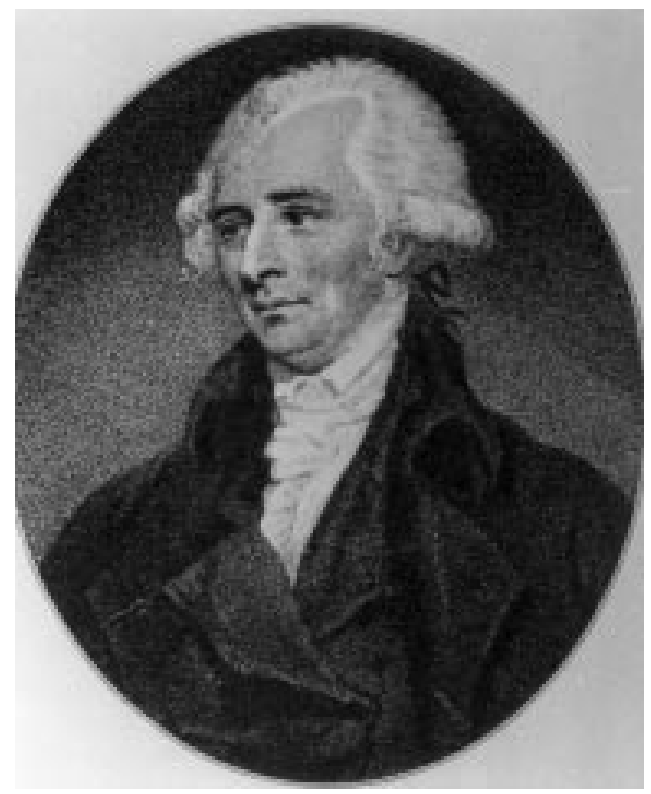

Figure 1 Dr William Buchan (1729-1805).

ridicule, and is injurious to the true interests of society ... The cure of disease is doubtless a matter of great importance; but the preservation of health is of still greater ... It is not to be supposed, that men can be sufficiently upon their guard against diseases, who are totally ignorant of their causes ... Indeed, men of every occupation and condition of life might avail themselves of a degree of medical knowledge ..."

Buchan acknowledged the influence that William Cadogan's pamphlet ${ }^{3}$ had had on him. Certainly the advice he gave on the care of infants, their diet, their clothing and their need for fresh air and exercise was similar and full of common sense.

\section{On the care of infants ${ }^{2}$}

". . .almost half of the children born in Great Britain die under twelve years of age . . . It may seem strange that man, notwithstanding his superior reason, should fall so far short of other animals in the management of his young ... Nothing can be more preposterous than a mother who thinks it below her to take care of her own child ... Every mother who 
can, ought certainly to (breastfeed) ... A child, by being brought up under the mother's eye, not only secures her affections, but may reap all the advantages of a mother's care ... It is indeed to be regretted, that more care is not bestowed in teaching the proper management of children to . . mothers ... It is their province, not only to form the body, but also to give the mind its most early bias ... Nor have physicians themselves been sufficiently attentive to the management of children: that has been generally considered as the sole province of old women ... Were physicians more attentive to the diseases of infants, they would not only be better qualified to treat them when sick, but likewise to give useful directions for their management when well ... It is really astonishing, that so little attention should be paid to the preservation of infants ... Mankind are too apt to value things according to their present, not their future, usefulness."

\section{On breast feeding ${ }^{2}$}

"The mother's milk, or that of a healthy nurse, is unquestionably the best food for an infant. Neither art nor nature can afford a proper substitute for it ... A child, soon after birth, shows an inclination to suck; and there is no reason why it should not be gratified. It is true, the mother's milk does not always come immediately after the birth; but this is the way to bring it: besides, the first milk that the child can squeeze out of the breast answers the purpose of cleansing, better than all the drugs in the apothecary's shop, and at the same time prevents inflammations of the breast, fevers, and other diseases ... . If the mother or nurse has enough milk, the child will need little or no other food before the third or fourth month."

In many other ways Buchan was ahead of his time. His account of how to take a medical history is remarkably modern. He was also an advocate of national service for boys, of eugenics, and of the use of the law to improve public health. As a prescriber he was cautious:

\section{On the use of medicines ${ }^{2}$}

"I think the administration of medicine always doubtful, and often dangerous, and would much rather teach men how to avoid the necessity of using them, than how they should be used.

One of the most common faults of those who nurse for hire, is to dose children with stupefactives, or such things as lull them asleep ... If a mother on visiting her child or nurse finds it always asleep, I would advise her to remove it immediately; otherwise it will soon sleep its last."

Nothing demonstrates better Buchan's interest in public health and the prevention of disease than his views on inoculation against smallpox, more than 20 years before the publication of Jenner's introduction of vaccination.

\section{On inoculation against smallpox}

"It is a most contagious malady; and had, for many years, proved the scourge of Europe ...no disease, after it has formed, baffles the powers of medicine more effectually than the smallpox, yet more may be done before hand, as almost all the danger from it may be prevented by inoculation ... In Turkey, from whence we learned the practice, the women communicate the disease to children ... The most proper age for inoculation is betwixt three and five ... In a natural way, one in four or five generally dies; but by inoculation not one in a thousand ... though it may seem paradoxical, the artificial method of communicating the disease, could it be rendered universal, would amount to nearly the same as rooting it out.

The first step towards rendering the practice universal, must be to remove the religious prejudices against it . . . The next thing requisite is to put it in the power of all ... we would recommend it to the Faculty to inoculate the children of the poor gratis . .. it is surely in the power of any state to render the practice general ... The best way to promote it would be to employ a sufficient number of operators at the public expense to inoculate the children of the poor ... A small premium to enable mothers to attend their children while under the disease, would be a sufficient inducement . . There is no doubt that inoculators will daily became more numerous. We would therefore have every parish in Britain to allow one of them a small annual salary for inoculating all the children of the parish at a proper age ... there is little reason to doubt that the practice will become general. Whenever this shall become the case, more lives will be saved by inoculation alone, than are at present by all the endeavours of the Faculty."

In 1778 the elder Gregory died. Buchan had hoped to succeed him but when this did not happen he removed to London where he gained a considerable practice based on the Chapter Coffee-house near St Paul's, a favourite haunt of literary men. "Full of anecdote, of agreeable manners, benevolent and compassionate, he was unsuited to make or keep a fortune: a tale of woe always drew tears from his eyes and money from his pocket." He published a number of other books including in 1803 his last great work: Advice to mothers on the subject of their own health and on the means of promoting the health, strength and beauty of their offspring. It was republished in France and America ${ }^{4}$ the following year.

In 1804 Buchan's health gave way, and on 25 February 1805 he died in his seventy sixth year. $\mathrm{He}$ was buried in the cloisters of Westminster Abbey.

Little is known of Buchan's family life except that he had a son, Alexander Peter Buchan, born in Sheffield in 1764. He followed his father into medicine, became a Licentiate of the College of Physicians in London, and was appointed a physician to the Westminster Hospital in 1813. Dying at the age of 61 in 1824 , he 
was also buried in the cloisters of Westminster Abbey. Besides writing a number of medical books, he re-edited in 1808 Dr George Armstrong's book on the diseases of children.

1 Ruhräj J. William Buchan, M.D. (1729-1805). Am f Dis Child 1931;42:403-8.
2 Buchan W. Domestic medicine or a treatise on the prevention and cure of diseases by regimen and simple medicines. 9 th ed. Dublin: H Chamberlain and others, 1784.

3 Cadogan W. An essay upon nursing and the management of children from their birth to three years of age. London: J Roberts, 1748.

4 Buchan W. Advice to mothers on the subject of their own health and on the means of promoting the health, strength and beauty of their offspring. Philadelphia: John Bioreu, 1804. 